AGH DRILLING, OIL, GAS • Vol. 30 • No. $1 \cdot 2013$

http://dx.doi.org/10.7494/drill.2013.30.1.151

\author{
Piotr Kosowski*
}

\title{
ANALYSIS OF THE CURRENT STATE AND TENDENCIES ON THE NATURAL GAS MARKET AND GAS STORAGE IN EUROPE ON THE BACKGROUND OF THE SITUATION IN POLAND**
}

\section{INTRODUCTION}

Gas market in Europe has recently experienced fast and radical changes. Their main causes were:

1. Supply and demand - recently we have natural gas oversupplies, which resulted in a drop of spot prices below the oil indexed price level. Accordingly, a number of natural gas receivers await changes in long-term contracts.

2. Law - the third liberalisation package aimed at further liberation of gas and electricity markets

3. Development of intersystem connections (interconnectors) - a number of European countries make or plan to make interconnectors. This will considerably improve the possibility of gas flow between markets of various countries in Europe, providing higher level of energy safety and stimulate the development of gas markets.

4. Change of attitudes and strategies of market participants - considerable part of traditional gas suppliers operate under long-term contracts. They have to compete with new entities, which can buy gas at lower (spot) prices, work out adjustment activities and employ different strategies. [IGU, 2012]

The present state and tendenciesof the natural gas market and gas storage in Europeare addressed and compared to the situation in Poland. The European countries were presented in view of their natural gas production, import and export against consumption (total and per capita) and the consumer structure. The changing consumption level as a function

* AGH University of Science and Technology

** Work performed within the statutory research of Faculty of Drilling, Oil and Gas AGH UST 
of the consumer structure and quantity of consumption was evaluated. The gas storage market in Europe was characterized, accounting for the existing and planned investments with special emphasis on storage capacity, injection and withdrawal capacity, and also types of storages. Changes in determining natural gas prices were also discussed.

\section{NATURAL GAS CONSUMPTION, EXPLOITATION AND IMPORT IN EUROPE}

Most of the natural gas consumption and the structure of its supplies in particular European countries are strongly diversified. The only common feature for most of these countries is the dependence on gas import. Only a few countries have a large annual home production; these are mainly:Norway, the Netherlands and Great Britain. A few countries produce gas on average level, e.g. Poland, but in most of the cases the production is negligible, if at all (Fig. 1). Besides, the conventional gas production in majority of discussed countries has a decreasing tendency and the production from unconventional sources still remains within the future plans.

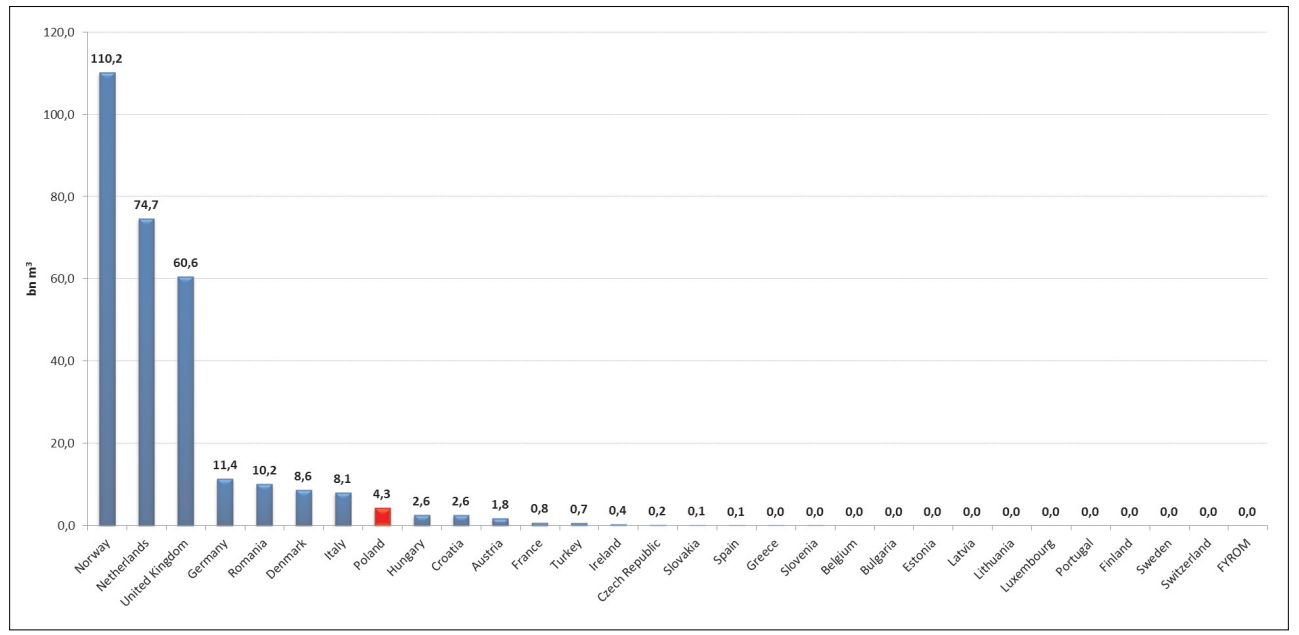

Fig. 1. Natural gas production in selected European countries in 2011 Source: Eurostat

On the background of relatively low annual production, areasonablyhigh level of consumption is observed in Europe and the biggest consumers are:Great Britain, Germany and Italy. Poland is ranked as 9th with its annual gas consumption of about $15 \mathrm{mld} \mathrm{m}^{3}$ (Fig. 2).

Import of large quantities of natural gas is anexpected consequence of this situation. Among the biggest European importers are: Germany, Great Britain and France. Poland occupies the 10th place in this classification with the annual import of ca. $10.5 \mathrm{bn} \mathrm{m}^{3}$ in 2011. 


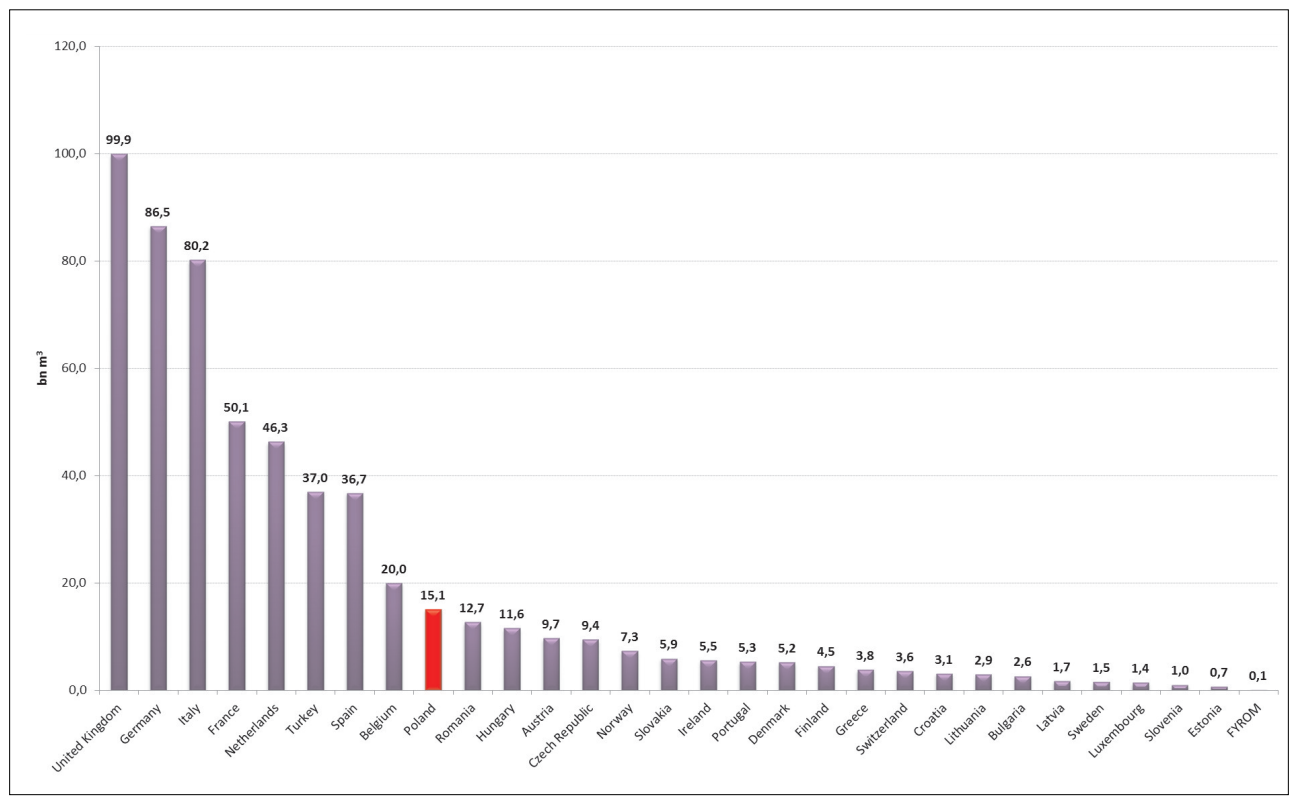

Fig. 2. Natural gas consumption in selected European countries in 2011 Source: Eurostat

As the European countries considerably differ in the number of population, therefore natural gas consumption should be given per capita (for one citizen). The highest consumption was observed in Holland and Luxemburg, exceeding 2.7 thousand $\mathrm{m}^{3}$ yearly per citizen (Fig. 3).

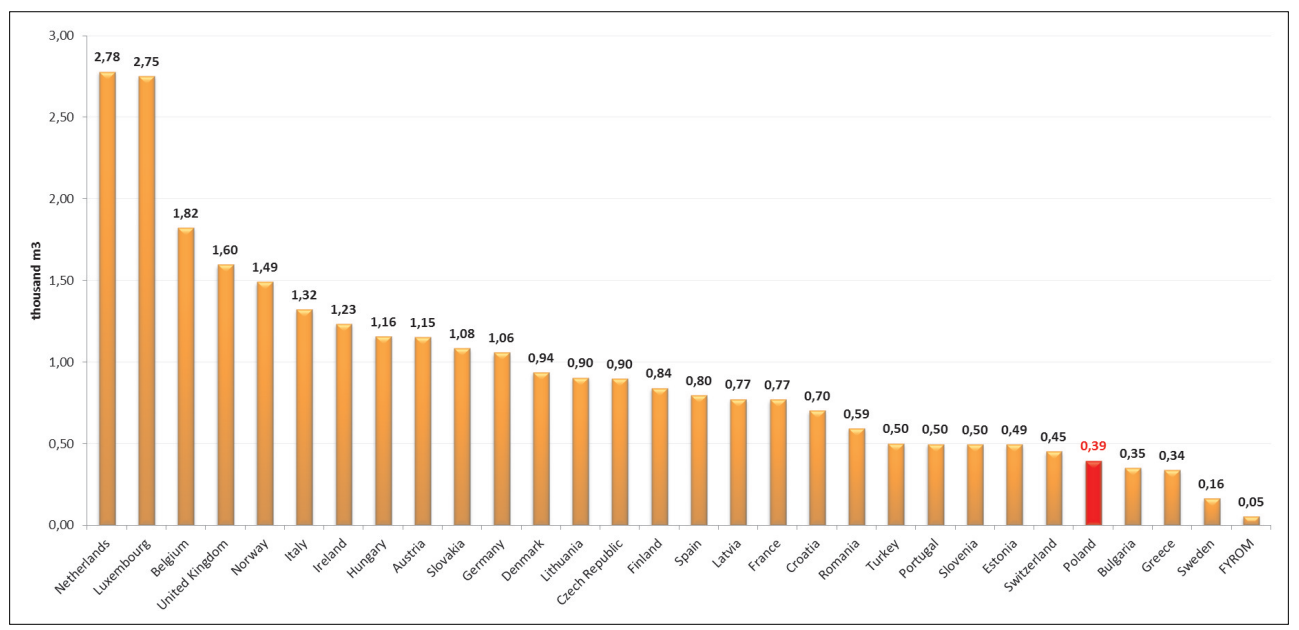

Fig. 3. Natural gas consumption per capita in selected European countries in 2011 Source: calculations based on Eurostat data 
The consumption of only about $390 \mathrm{~m}^{3}$ per capita in Poland is not impressive on this background. For instance, the annual consumption of Poland's neighbour countries per capitais: Germany $1060 \mathrm{~m}^{3}$, Slovakia $-1080 \mathrm{~m}^{3}$, Czech Republic and Latvia $-900 \mathrm{~m}^{3}$. The analysis of data reveals that only four countries have lower consumption: Bulgaria, Greece, Sweden and Macedonia.

The natural gas consumption versus GDP per capita presented in Figure 4 shows a dependence between the level of affluence, measured by GDP, and natural gas consumption. Generally, the higher the GDP, the higher the natural gas consumption. Poland has relatively low GDP and low gas consumption per capita. This is also an indicative of comparatively high potential of natural gas market in Poland, related with expected and desired increase of level of wealth.

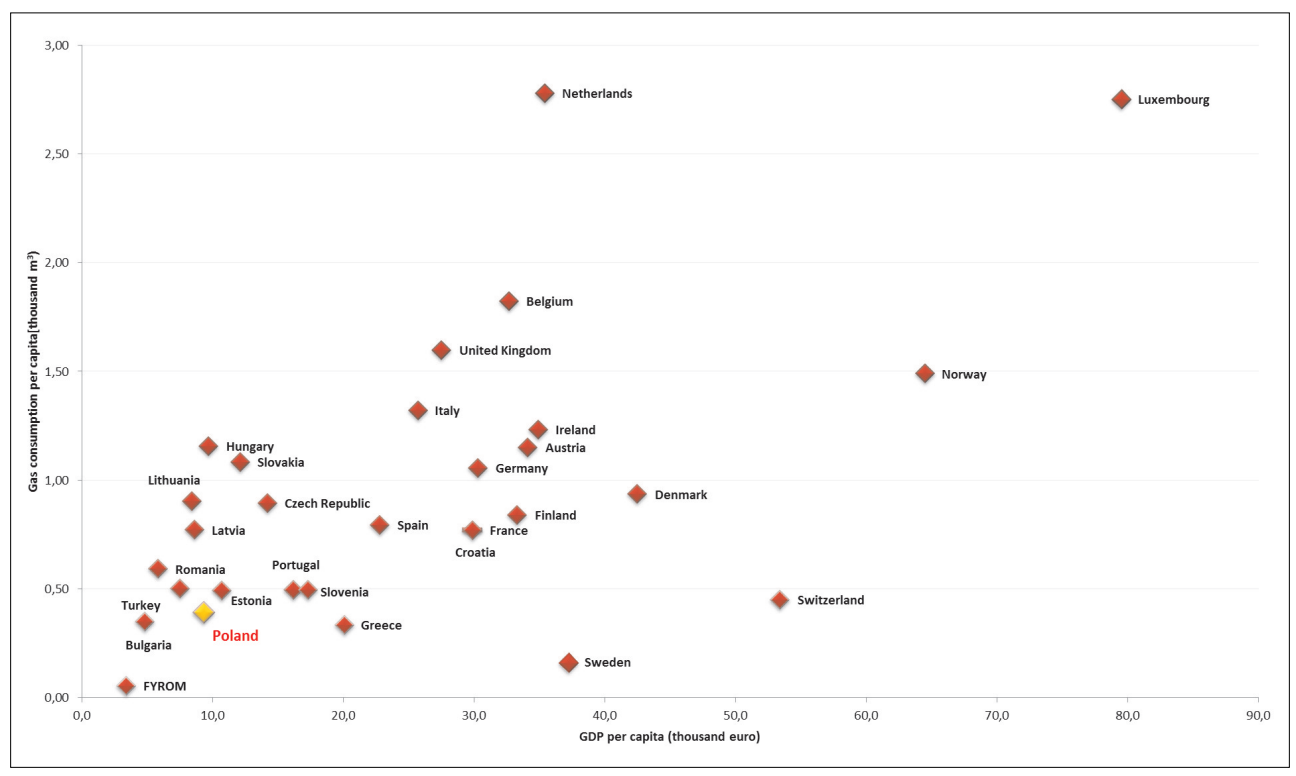

Fig. 4. Natural gas consumption per capitavs. GDP per capita in selected European countries in 2011 Source: calculations based on Eurostat data

The structure of natural gas consumers is also diversified in Europe (as of 2011). The share of households ranges from $0 \%$ in Macedonia to over 38\% in Switzerland. In the case of the biggest gas consumers (total volume) the share usually exceeds the Europe's average (except for countries where climatic conditions have a significantimpact on consumption, as in Turkey and Spain). In Poland $27.7 \%$ of total gas consumption comes from households, exceeding the Europe's average value.

The share of the services sector ranges from $0.4 \%$ (Norway) to $19.1 \%$ (Switzerland) of total consumption. Poland occupies a relatively high rank in this classification with $15.9 \%$ of consumed gas used by this sector of economy.

The share of energy and industrial sector and other consumers ranges between $42.5 \%$ in Switzerland to $99.6 \%$ in Norway. In Poland this group consumes about $56.5 \%$ of natural gas. 
Variability is an important factor describing natural gas consumption. The monthly coefficient of variation (ratio of the standard deviation to the mean)for natural gas consumption in the analyzed countries is different in various countries and ranges between $11.64 \%$ (Portugal) and $57.62 \%$ (Norway). Despite relatively severe climatic conditions, Poland with its variability at $28.44 \%$ is below the European average value.

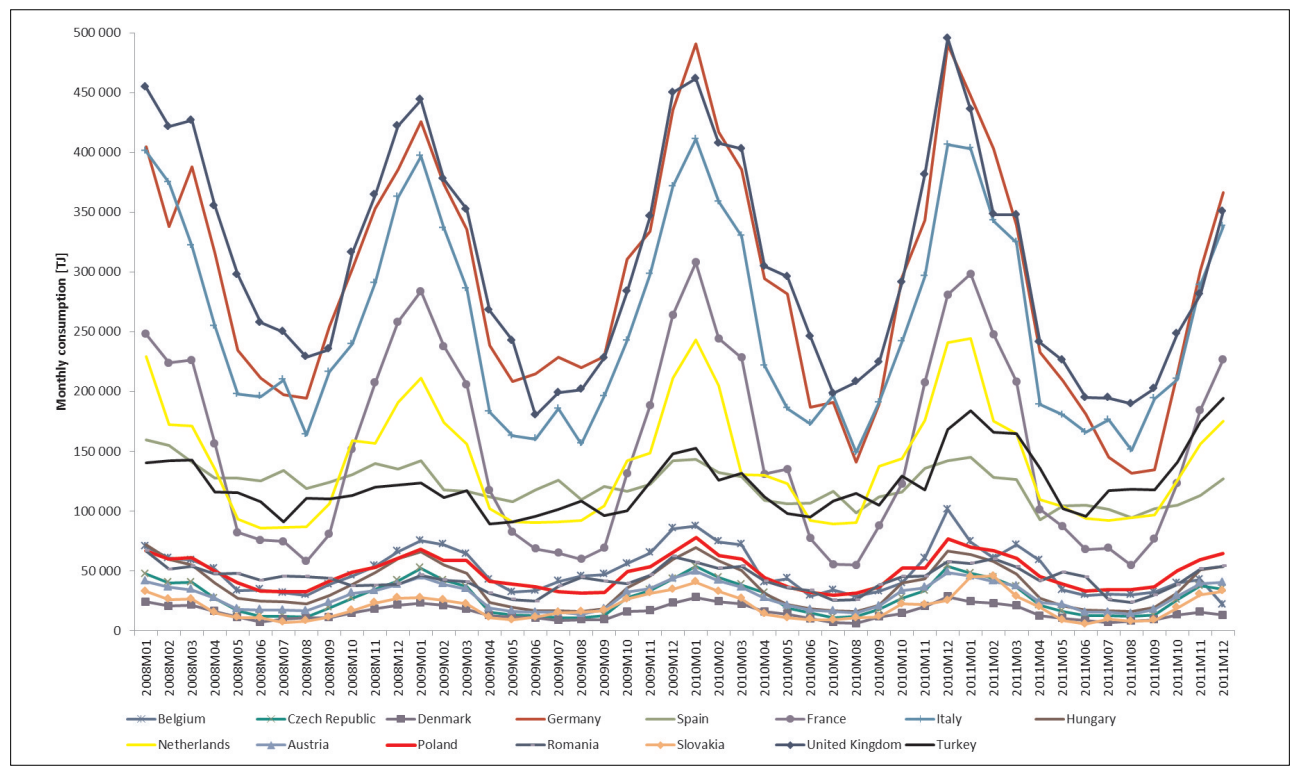

Fig. 5. Monthly average natural gas consumption in selected European countries in 2008-2011 Source: Eurostat

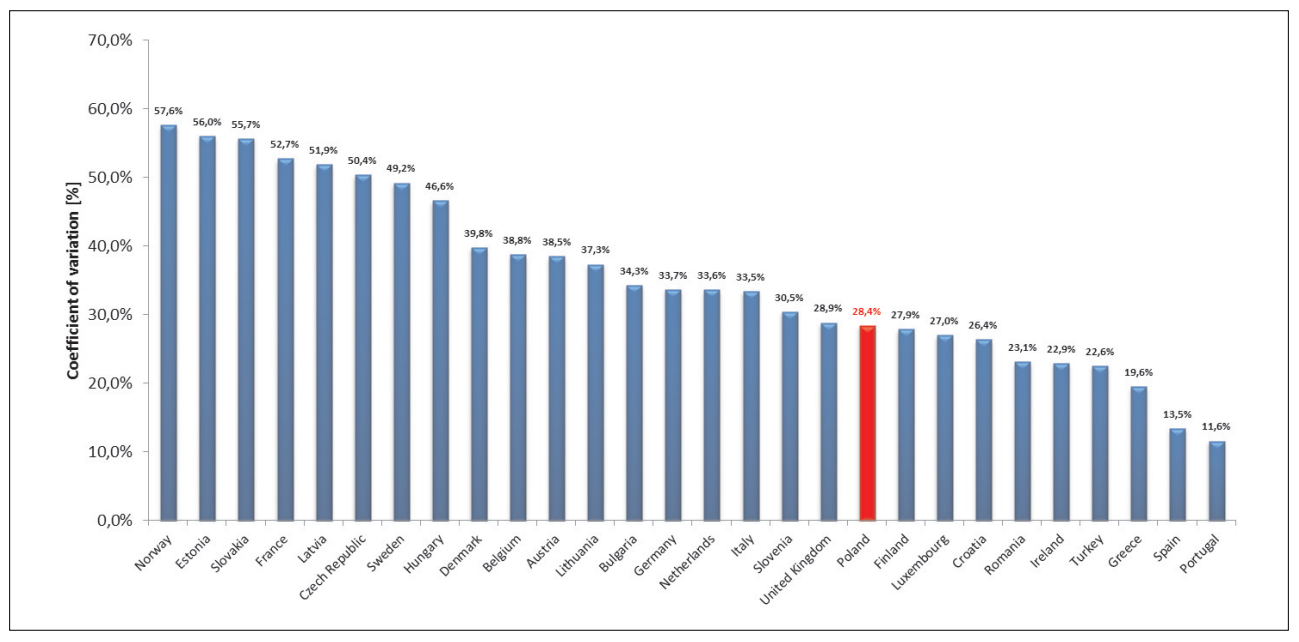

Fig. 6. Coefficient of variation of monthly gas consumption in selected European countries in 2011 Source: calculations based on Eurostat data 


\section{GAS STORAGE IN EUROPE}

In 2012 the total working storage capacity in Europe (without Russia) was $129.2 \mathrm{bn} \mathrm{m}^{3}$, withdrawal capacity was $2.33 \mathrm{bn} \mathrm{m}^{3} / \mathrm{d}$, and injection capacity was $1.13 \mathrm{bn} \mathrm{m}^{3} / \mathrm{d}$. Successive $63.39 \mathrm{bn} \mathrm{m}^{3}$ of working capacity, $0.61 \mathrm{bn} \mathrm{m}^{3} / \mathrm{d}$ of withdrawal capacity and $0.27 \mathrm{bn} \mathrm{m}^{3} / \mathrm{d}$ of injection capacity are at the construction and planning stage, which is indicative of a rapid development of gas storage market in Europe (Fig. 7).

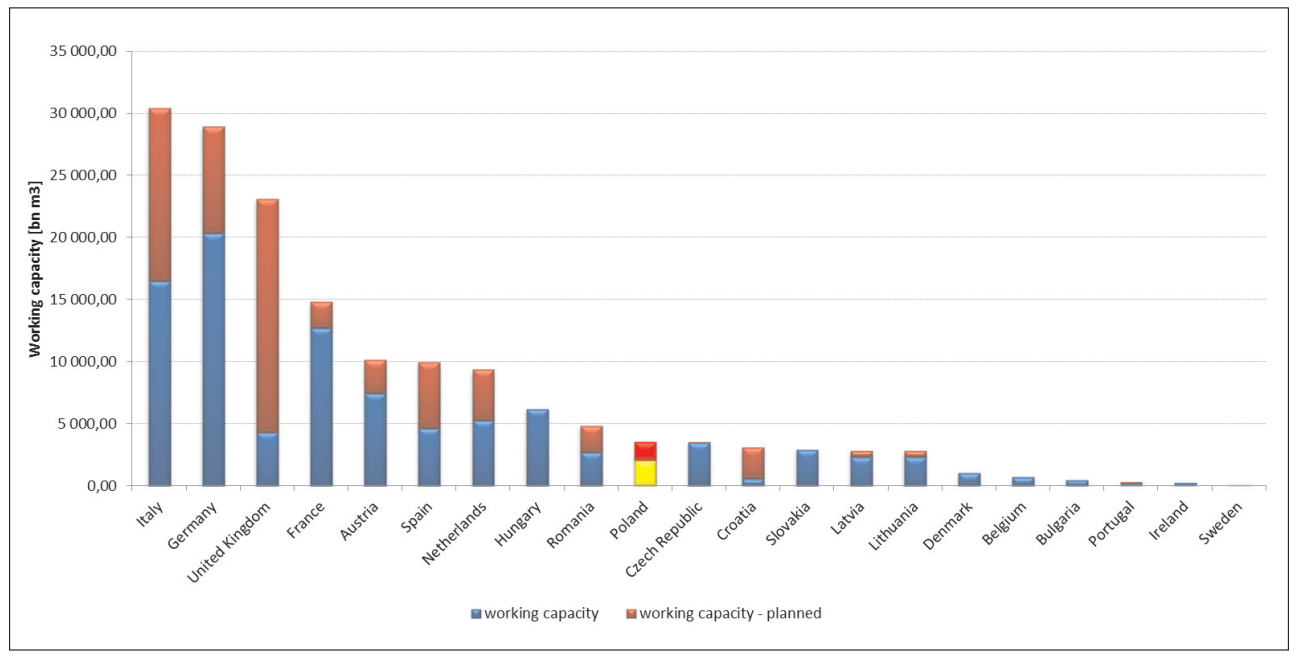

Fig. 7. Existing and planned working capacity in selected European countries in 2012 Source: GIE

The biggest workingcapacities of $32.97 \mathrm{bn} \mathrm{m}^{3}$ are reported for Ukraine, which is over $25.5 \%$ of total volume of available capacity in the analyzed countries. Then follow: Germany $\left(20.37 \mathrm{bn} \mathrm{m}^{3}, 15.78 \%\right.$ of total value), Italy $\left(16.49 \mathrm{bn} \mathrm{m}^{3}, 12.77 \%\right)$ and France $\left(12.7 \mathrm{bn} \mathrm{m}^{3}\right.$, $9.83 \%)$.

The biggest withdrawal capacities are noted for Germany $\left(0.5 \mathrm{bn} \mathrm{m}^{3} / \mathrm{d}, 21.41 \%\right.$ of total value), then France $\left(0.34 \mathrm{bn} \mathrm{m}^{3} / \mathrm{d}, 14.47 \%\right)$, Ukraine $\left(0.3 \mathrm{bn} \mathrm{m}^{3} / \mathrm{d}, 12.92 \%\right)$ and Italy $\left(0.28 \mathrm{bn} \mathrm{m}^{3} / \mathrm{d}, 12.19 \%\right)$.

As far as the planned investments are concerned, the biggest increase of working capacity was observed in Great Britain $\left(18.8 \mathrm{bn} \mathrm{m}^{3}, 29.65 \%\right.$ of total increase), Italy (13.94bn $\mathrm{m}^{3}$, $21.99 \%)$ and Germany $\left(8.52 \mathrm{bn} \mathrm{m}^{3}, 13.54 \%\right)$. In the case of withdrawal capacity the biggest growth was planned in Spain $\left(0.12 \mathrm{bn} \mathrm{m}^{3} / \mathrm{d}, 19.18 \%\right.$ of total increase), Germany $\left(0.12 \mathrm{bn} \mathrm{m}^{3} / \mathrm{d}\right.$,

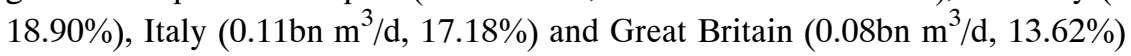

Working capacities in Poland constitute now $1.59 \%$ of total capacity in Europe, and withdrawal capacities are $1.69 \%$. After completing all planned investments these percentages are expected to increase up to $2.36 \%$ and $3.21 \%$, respectively. 


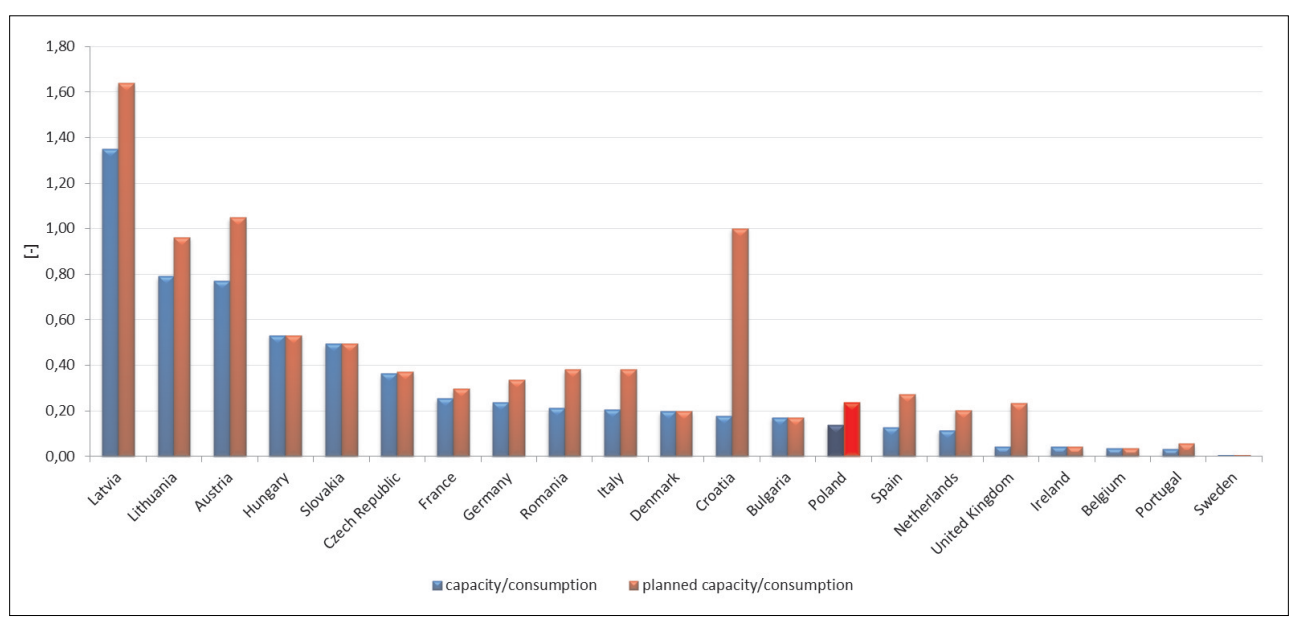

Fig. 8. Existing and planned share of working capacity in consumption in selected European countries in 2012 Source: calculations based on GIE data

The working capacity to annual consumption ratio is interesting as it shows what percentage of annual consumption in a given country can be covered from gas storages. At the same time this parameter is an indicator of energy safety in a given country (Fig. 8).

The highest value is observed in Latvia (1.35), which means that a given country can store $135 \%$ of its annual gas consumption. Then follow Lithuania (0.79), Austria (0.77) and Hungary (0.53). This ratio stays within 0.21 to 0.25 for Germany, France and Italy. A surprisingly low value (0.04) was noted for Great Britain. This seems to be one of the most plausible causes of intense development of gas storages in that country. In Poland underground gas storages can store gas covering only $14 \%$ of yearly consumption, and after finishing the planned investments the ratio is expected to increase to $24 \%$.

Figure 9 illustrates the share of the storage capacity in the annual consumption against the share of production in the annual consumption. The analyzed countries can be divided into three groups. The first one, i.e. Holland and Denmark, are capable of meeting their entire demand from own sources, therefore have relatively small storage capacities. The second group, i.e. Great Britain, Croatia and Romania, can cover over 50\% of their demand and do not have big storage capacities. In the remaining countries (Poland including) only a little part of the demand can be covered from the domesticproduction. It is worth noting that Polandhas the biggest share of own production among other countries in this group. Generally, the countries differ in their storage capacityfrom being able to store gas for over a year, to practically not having any reserves.

The influence of consumption per capita on storage capacity demand is clearly visible in Figure 10, which represents a dependence between withdrawal capacity per capita and consumption per capita. If Poland observes the expected increase of natural gas consumption, then the need for storage and withdrawal capacities will certainly grow up. 


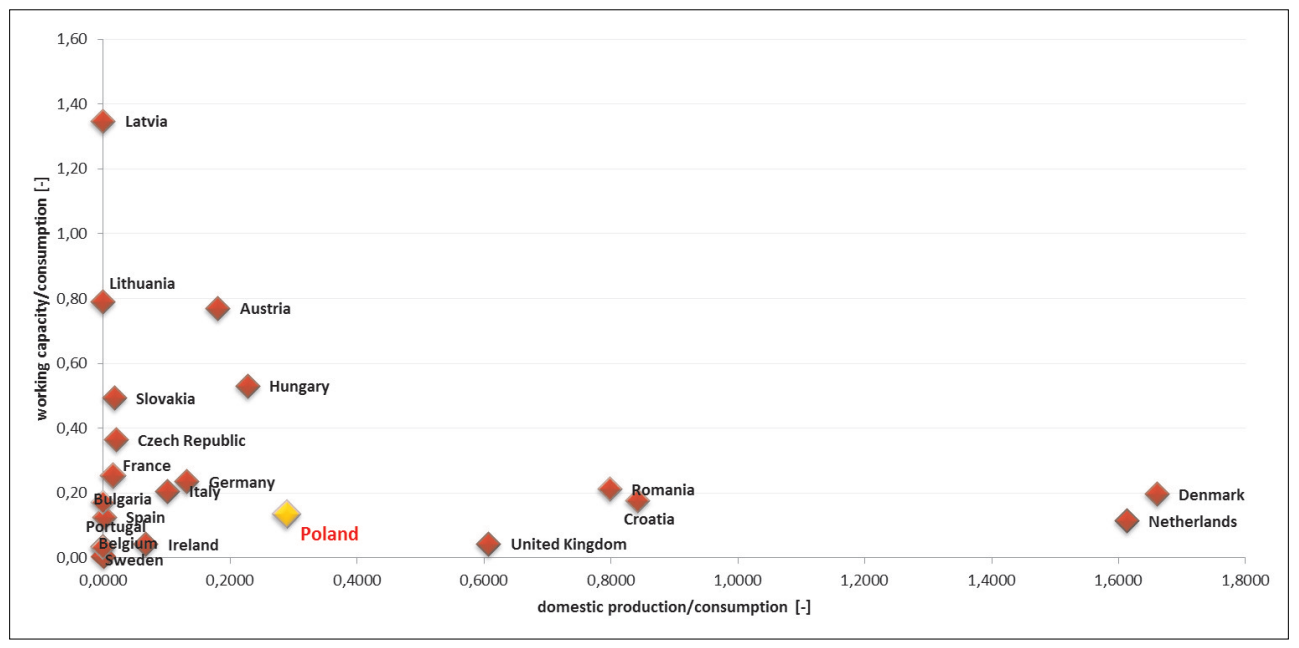

Fig. 9. Share of capacity in consumption vs.domestic production in consumption in selected European countries in 2012

Source: calculations based on GIE data

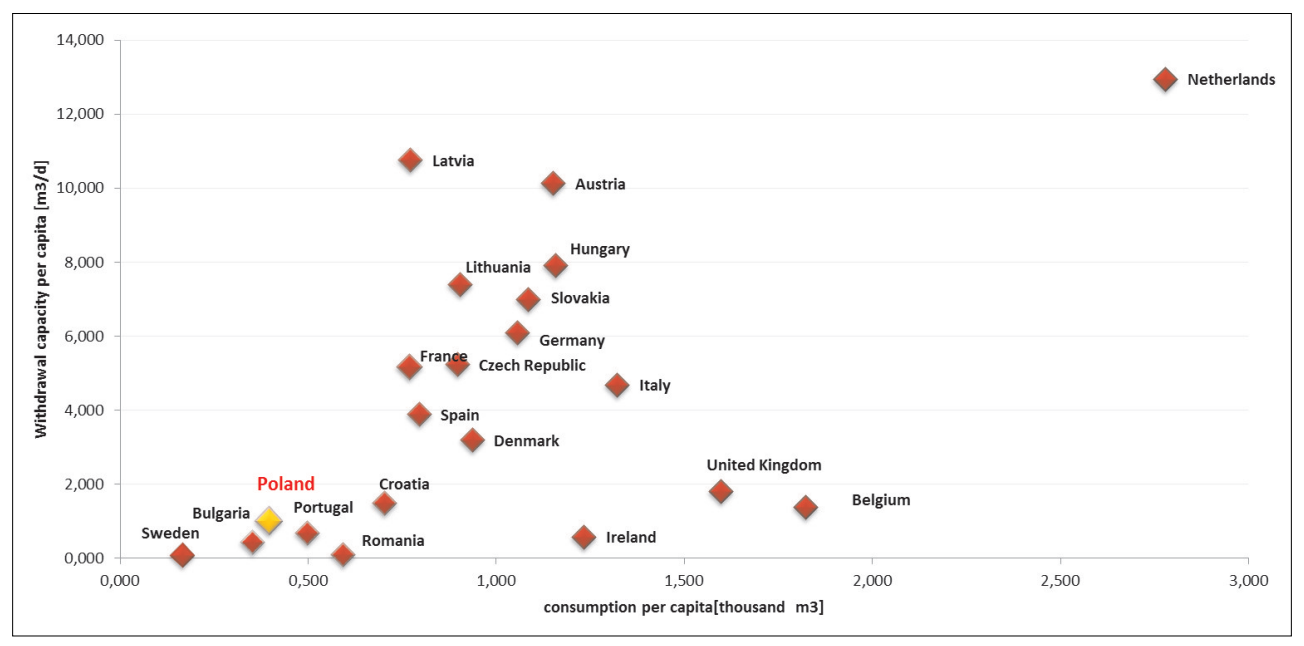

Fig. 10. Withdrawal capacity per capitavs. consumption per capita in selected European countries in 2012

Source: calculations based on Gas Infrastructure Europe data

\section{TYPES OF UNDERGROUND GAS STORAGES IN EUROPE}

Most of underground gas storages in Europe are placed in depleted oil and natural gas reservoirs; presently their share reaches $69 \%\left(64.68 \mathrm{bn}^{3}\right)$ of available storage capacities. 
The second place is occupied by storages located in aquifers, giving $14.85 \%\left(13.94 \mathrm{bn} \mathrm{m}^{3}\right)$ and the third by salt caverns- $14.04 \%\left(13.18 \mathrm{bn}^{3}\right)$ of total capacity. A minor share belongs to LNG storages $(2.19 \%)$. After completing the planned investments, the structure will slightly change owing to the increasing importance of storages in salt cavers. Their share is expected to increase to over $18 \%\left(28.36 \mathrm{bn}^{3}\right)$. The storages in depleted deposits will remain most popular, giving $66.2 \%\left(103.47 \mathrm{bn}^{3}\right)$ [GIE, 2012].

Analyzing the structure of withdrawal capacity of storages one can easily see the increasing role of the cavern storages. Despite the fact that their share in available capacity potential is only $14.04 \%$, the percentage in the withdrawal capacity is almost $30 \%$. The biggest withdrawal capacities still come from reservoir storages and correspond to $47.75 \%$ of the total. There can be observed a huge flexibility of LNG storages, with $2.19 \%$ of the capacity, which bring about $10.43 \%$ of accessible withdrawal capacity. After completing planned investments, the structure of available withdrawal capacity will slightly change the share of cavern storages will increase to $31.52 \%$ and that of aquifer storages will decrease to $10.69 \%[\mathrm{GIE}, 2012]$.

\section{NATURAL GAS PRICES}

Significant changes have been observed in natural gas pricing in Europe. The share of the volume of gas sold in Europe at oil indexed prices dropped down from 79 to $59 \%$, and the amount of gas sold at spot prices increased from 15 to $40 \%$ over a 5-year period (2005-2010) [IGU, 2012]. This clearly shows the growing significance of gas hubs and spot prices on the European market, and also readiness of companies to undertake the risk in exchange for the access to market prices.

Prices based on gas hubs are a relatively new phenomenon in Europe. The oldest one, i.e. NBP has been operational for only 16 years. Presently eight big European hubs can be enumerated:

- NBP (Great Britain) - active since 1996. The most liquid hub in Europe. Most of the gas in Great Britain is priced according to it,

- TTF (Holland) - established in 2003. Most liquid hub in continental Europe. Prices are generally close to NBP,

- ZEE (Belgium) - established in 1999,

- NCG\&Gaspool (Germany) - two major gas hubs in Germany,

- PEG (France),

- CEGH Baumgarten (Austria),

- PSV (Italy).

Most of active European hubs concentrate in NW Europe around NBP, TTH and ZEE, which are physically connected by interconnectors. In 2010 they were responsible for $85 \%$ of transactions and $50 \%$ of physical deliveries of gas on that marker. In 2010 a total of $200 \mathrm{bn} \mathrm{m} 3$ of natural gas was sold by hubs, which makes almost $40 \%$ of European consumption [IGU, 2012]. 


\section{CONCLUSION}

Natural gas markets, in particular European countries, undergo rapid changes and are transformed from a closed to the free market model. There are still a number of market, technical and legal limitations, but the creation of a common gas market seems inevitable. Additional factors stimulating changes are the two on-going revolutions. The first one is the production of gas from unconventional sources, which will probably change the World's energy markets and enable tapping into huge natural gas resources. The other lies in overcoming one of the biggest limitations of free gas trade, i.e. lack of other efficient transport means than gas pipelines. Thanks to the development of LNG technology the global gas market can be created, as it was the case for oil.

Gas market in Europe will certainly become more competitive and new companies will appear on it. This will increase the variability of the market, including the price changes, which will be a consequence of,e.g.abandoning oil indexed pricing of natural gas. Changes on the gas market are also a source of gas storage evolution, especially the more flexible ones (mainly salt caverns). At present the customers are offered a number of services, from long-term to short-term storage packages. These services may be also granted on periodic or continuous basis, depending on the available capacities. New clients appear on the market, in that banks and financial institutions. Despite the fact that traditional seasonal storage still plays an important role, the share of other, flexible services on the storage market will certainly grow in power.

\section{REFERENCES}

[1] Eurostat. http://epp.eurostat.ec.europa.eu/portal/page/portal/eurostat/home/

[2] Gas Infrastructure Europe, http://www.gie.eu.com/download/maps/GSE_STOR_MAPDATA_MAY2012.xls

[3] International Gas Union, Programme Committee C: Gas Markets, 2009-2012 Triennium Work Report, June 2012.

[4] International Gas Union, Working Committee 2: Underground Gas Storage, 20092012 Triennium Work Report, June 2012. 